
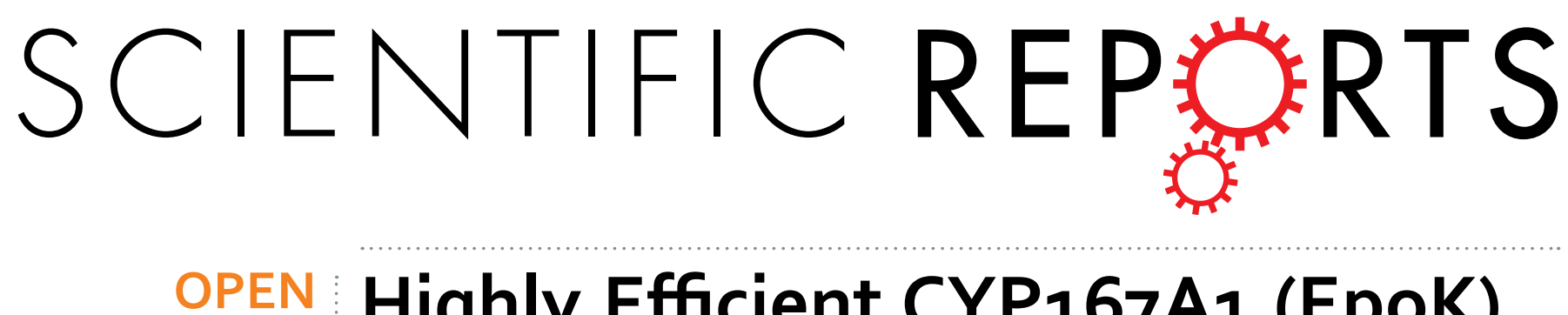

\title{
Highly Efficient CYP167A1 (EpoK) dependent Epothilone B Formation and Production of 7-Ketone
}

Received: 30 May 2015

Accepted: 11 September 2015

Published: 08 October 2015
Epothilone D as a New Epothilone Derivative

\author{
Fredy Kern ${ }^{1}$, Tobias K. F. Dier ${ }^{2}$, Yogan Khatri ${ }^{1}$, Kerstin M. Ewen ${ }^{1}$, Jean-Pierre Jacquot ${ }^{3}$, \\ Dietrich A. Volmer ${ }^{2}$ \& Rita Bernhardt ${ }^{1}$
}

Since their discovery in the soil bacterium Sorangium cellulosum, epothilones have emerged as a valuable substance class with promising anti-tumor activity. Because of their benefits in the treatment of cancer and neurodegenerative diseases, epothilones are targets for drug design and pharmaceutical research. The final step of their biosynthesis - a cytochrome $\mathrm{P} 450$ mediated epoxidation of epothilone C/D to A/B by CYP167A1 (EpoK) - needs significant improvement, in particular regarding the efficiency of its redox partners. Therefore, we have investigated the ability of various hetero- and homologous redox partners to transfer electrons to EpoK. Hereby, a new hybrid system was established with conversion rates eleven times higher and $V_{\max }$ of more than seven orders of magnitudes higher as compared with the previously described spinach redox chain. This hybrid system is the most efficient redox chain for EpoK described to date. Furthermore, $\mathrm{P}_{4505}$ from So ce56 were identified which are able to convert epothilone $\mathrm{D}$ to $14-\mathrm{OH}, 21-\mathrm{OH}, 26-\mathrm{OH}$ epothilone $D$ and 7-ketone epothilone $D$. The latter one represents a novel epothilone derivative and is a suitable candidate for pharmacological tests. The results revealed myxobacterial $\mathrm{P}_{\mathbf{4}} \mathrm{50s}$ from $\mathrm{S}$. cellulosum So ce5 6 as promising candidates for protein engineering for biotechnological production of epothilone derivatives.

In 2012, the World Human Organization's global target of reducing premature mortality from non-communicable diseases (e.g. cancer) by $25 \%$ was set to be achieved by $2025^{1}$. To reach this ambitious target, population-based cancer registries and surveillance systems ${ }^{2}$ as well as fundamental cancer research are essential. For decades, chemotherapy has been the leading therapeutic approach in the treatment of cancer. Interestingly, more than $60 \%$ of anticancer agents currently in use are derived from natural sources, including plants, marine organisms and microorganisms ${ }^{3}$. Among these compounds, agents blocking mitosis rate by targeting microtubules belong to the most efficient anti-cancer drugs identified to date ${ }^{4}$. One member of the group of microtubule-stabilizing agents are epothilones, which were first discovered in 1987 by Gerth and coworkers as antifungal compounds naturally produced by the soil bacterium Sorangium cellulosum ${ }^{5,6}$. After the discovery of the cytotoxic activity of epothilones against a number of tumor cell lines in $1995^{7}$, many studies and clinical trials with epothilones were published, with epothilone $\mathrm{D}$ and $\mathrm{B}$ emerging as the most promising candidates for treatment of cancer.

${ }^{1}$ Department of Biochemistry, Saarland University, 66123 Saarbrücken, Germany. ${ }^{2}$ Institute of Bioanalytical Chemistry, Saarland University, 66123 Saarbrücken, Germany. 3Unité Mixte de Recherches, 1136 Interaction arbres microorganismes INRA, Nancy University, 54506 Vandoeuvre-lès-Nancy cedex, France. Correspondence and requests for materials should be addressed to R.B. (email: ritabern@mx.uni-saarland.de) 


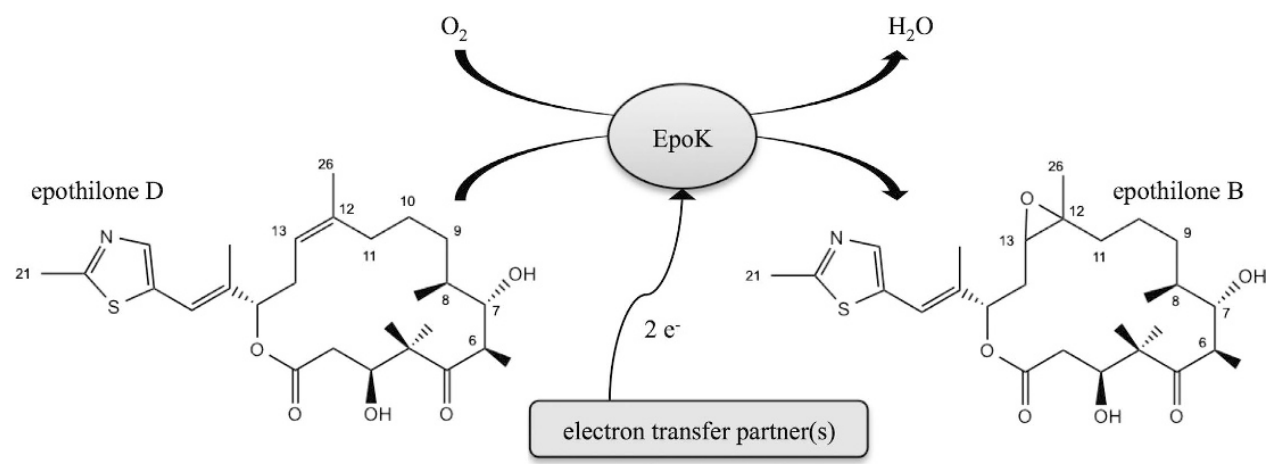

Figure 1. Conversion of epothilone D to B catalyzed by EpoK in S. cellulosum So ce90; electron transfer partners are unknown.

With respect to favorable characteristics as anticancer drugs, only derivatives of epothilone $\mathrm{D}$ and $\mathrm{B}$ have reached the stage of clinical investigation. Among those, Ixabepilone (an epothilone B analogue) is the only approved drug in cancer therapy to date ${ }^{8}$. Moreover, further studies have recently revealed additional benefits for treatment of Alzheimer's and Parkinson's disease with epothilone $\mathrm{D}^{9,10}$. Because of the variety of possible medical applications, epothilone D and its derivatives are most interesting targets for pharmaceutical and medical investigations.

The biosynthesis of epothilone $\mathrm{D}$ was first proposed by sequence determination of the biosynthetic gene cluster in S. cellulosum So ce $90^{11}$ and evaluated with the cloning of the complete gene cluster from S. cellulosum SMP44 into S. coelicolor ${ }^{12}$. It was demonstrated that the myxobacterial CYP167A1 (EpoK) is responsible for the final step of epothilone biosynthesis (epoxidation of epothilone D to B (Fig. 1), and epothilone $\mathrm{C}$ to $\mathrm{A}$, respectively). In general, cytochrome $\mathrm{P} 450$ enzymes (P450) are versatile enzymes catalyzing a variety of reactions ${ }^{13}$, a characteristic that makes them essential components of biotechnological and pharmaceutical research ${ }^{14}$. But P450s belong to the external monooxygenases and thus require electron supply from external redox partners ${ }^{15}$. Because neither the natural nor an efficient heterologous redox system supporting EpoK are known, the establishment of a whole-cell system in E. coli could not be achieved to date.

Although it was reported early on that an artificial redox chain consisting of spinach ferredoxin and ferredoxin reductase can support EpoK activity, the efficiency of the reaction was rather low. For the C-terminal his-tagged EpoK $(1.5 \mu \mathrm{M})$, only $60 \%$ yields were observed after one hour at $30^{\circ} \mathrm{C}$ when $100 \mu \mathrm{M}$ epothilone D was used as substrate ${ }^{12}$. Putidaredoxin and putidaredoxin reductase from Pseudomonas putida also turned out not to be efficient enough to be a good alternative for the spinach system $^{16}$. Therefore, it is paramount to establish an efficient redox chain to unlock the biotechnological potential of EpoK.

In this study, we first investigated homo- and heterologous electron transfer systems for an in vitro conversion of epothilone $\mathrm{D}$ by EpoK. Therefore, we studied bovine adrenodoxin $\left(\mathrm{Adx}_{4-108}\right)$ and adrenodoxin reductase (AdR), electron-transfer-protein $1\left(E t p 1^{\mathrm{fd}}\right)$ and its autologous adrenodoxin reductase homologue 1 (Arh1) from Schizosaccharomyces pombe, and myxobacterial ferredoxins and ferredoxin reductase from S. cellulosum So ce56 (Fdx2/FdR_B and Fdx8/FdR_B), as well as a novel hybrid electron transfer system for P450s, ferredoxin (SynFdx) from Synechocystis and ferredoxin $\mathrm{NADP}^{+}$reductase (FNR) from Chlamydomonas reinhardtii.

In addition, we examined selected P450s from the related strain S. cellulosum So ce56 for a conversion of epothilone D. P450s of this strain were recently investigated by our group and exhibited novel functionalities and a broad substrate range ${ }^{17-20}$. Bioinformatics study revealed some of these P450s to be closely related to EpoK. As a result, the members of the CYP109, CYP260, CYP264 and CYP267 families as well as CYP265A1 and CYP266A1 from So ce56 were selected and implemented for in vitro conversions. The resulting products were subsequently analyzed via HPLC and LC-MS/MS. All structure proposals were tentatively assigned by LC-MS/MS and proposed collision-induced dissociation spectra are presented.

\section{Results}

Investigated electron transfer proteins: important characteristics. During our studies, several homologous and heterologous electron transfer systems were investigated. The general characteristics of the respective components are listed in Table 1 for ferredoxins and Table 2 for reductases, respectively. It is noteworthy that the redox potential of ferredoxins is decreasing from $-344 \mathrm{mV}$ for $\mathrm{Adx}_{4-108}$ to $-353 \mathrm{mV}$ for Etp $1^{\mathrm{fd}}$ and to a redox potential of $-380 \mathrm{mV}$ for ferredoxin (SynFdx) from Synechocystis. The ferredoxins $\mathrm{Adx}_{4-108}, \mathrm{Etp}^{\mathrm{fd}}$ and SynFdx belong to the [2Fe-2S]-type and Fdx2 and Fdx8 from So ce56 to the $[3 \mathrm{Fe}-4 \mathrm{~S}]$-type ferredoxins. Moreover, both eukaryotic reductases, AdR and Arh1, have a molecular 


\begin{tabular}{|l|c|c|c|c|c|c|}
\hline Name & Organism & $\begin{array}{c}\text { Amino } \\
\text { acids }\end{array}$ & $\begin{array}{c}\text { Molecular } \\
\text { weight }[\mathbf{k D a}]\end{array}$ & $\begin{array}{c}\text { Redox } \\
\text { potential } \\
{[\mathbf{m V}]}\end{array}$ & $\begin{array}{c}\text { Fe-S } \\
\text { cluster } \\
\text { type }\end{array}$ & Literature \\
\hline $\mathrm{Adx}_{4-108}$ & Bos taurus & 104 & 11.8 & -344 & {$[2 \mathrm{Fe}-2 \mathrm{~S}]$} & 62,66 \\
\hline $\mathrm{Etp1}^{\mathrm{fd}}$ & S. pombe & 127 & 14.1 & -353 & {$[2 \mathrm{Fe}-2 \mathrm{~S}]$} & 67 \\
\hline $\mathrm{Fdx} 2$ & $\begin{array}{c}\text { S. cellulosum So } \\
\text { ce56 }\end{array}$ & 101 & 11.2 & $/$ & {$[3 \mathrm{Fe}-4 \mathrm{~S}]$} & 31 \\
\hline $\mathrm{Fdx} 8$ & $\begin{array}{c}\text { S. cellulosum So } \\
\text { ce56 }\end{array}$ & 107 & 11.9 & $/$ & {$[3 \mathrm{Fe}-4 \mathrm{~S}]$} & 31 \\
\hline SynFdx & Synechocystis & 96 & 10.3 & -380 & {$[2 \mathrm{Fe}-2 \mathrm{~S}]$} & 35,68 \\
\hline
\end{tabular}

Table 1. Origins and properties of selected ferredoxins. (/: not described).

\begin{tabular}{|l|c|c|c|c|}
\hline Name & Organism & $\begin{array}{c}\text { Amino } \\
\text { acids }\end{array}$ & $\begin{array}{c}\text { Molecular } \\
\text { weight } \\
{[\mathbf{k D a}]}\end{array}$ & Literature \\
\hline AdR & Bos taurus & 492 & 50.3 & 69 \\
\hline Arh1 & S. pombe & 469 & 51.4 & 29 \\
\hline FdR_B & $\begin{array}{c}\text { S. cellulosum } \\
\text { So ce56 }\end{array}$ & 244 & 26.7 & 31 \\
\hline FNR & C. reinhardtii & 320 & 36.5 & $38,70-72$ \\
\hline
\end{tabular}

Table 2. Origins and properties of investigated reductases. The listed reductases contain flavin adenine dinucleotide and use both NADPH and NADH as a cofactor (Arh1 and FdR_B) with the preference for NADPH for FdR_B ${ }^{31}$, while AdR and FNR use NADPH only.
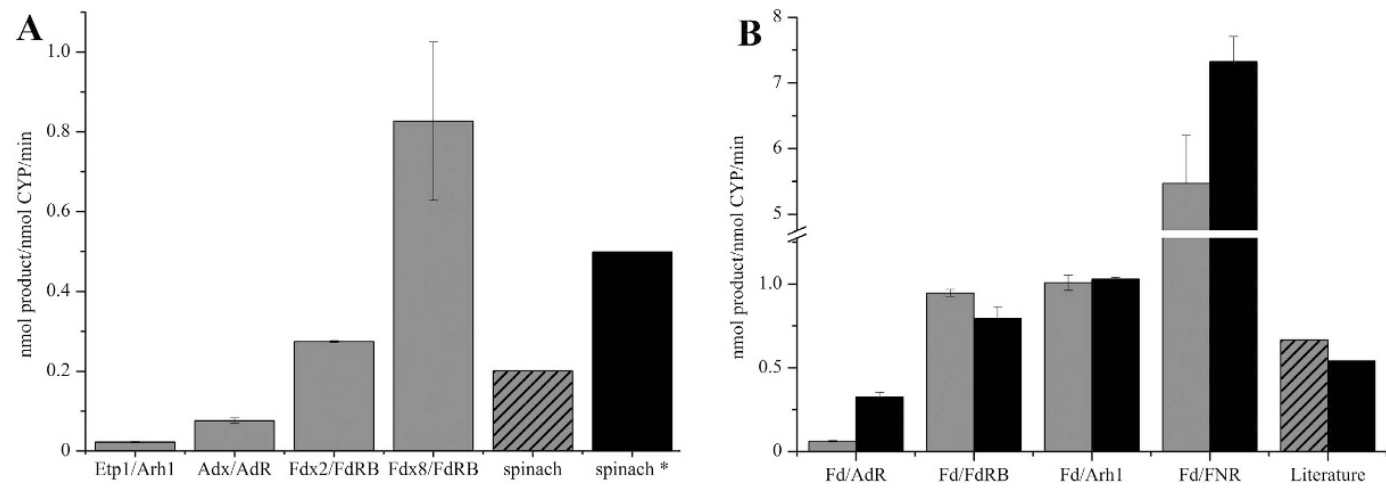

Figure 2. (A) Epothilone D conversions by EpoK with different electron transfer partners (spinach: ratio 1:100:0.025U; spinach*: ratio 1:100:0.125U for P450:Fdx:FdR; reductase in units); (B) Epothilone D conversions with EpoK, ferredoxin SynFdx (Fd) from Synechocystis and selected reductases (ratio 1:10:1 in grey bars and ratio 1:20:3 in black bars); bars designated as "Literature" were calculated from published data using spinach redox system: dashed ${ }^{12}$ and black bar $^{21}$

weight of around $50 \mathrm{kDa}$, almost twice the values for the comparatively small reductase FdR_B from $S$. cellulosum So ce56.

In vitro conversions of epothilone D by EpoK. EpoK was tested with a variety of electron transfer partners as shown in Fig. 2A. The redox systems Etp $1^{\mathrm{fd}} / \mathrm{Arh} 1$ from $S$. pombe and $\mathrm{Adx}_{4-108} / \mathrm{AdR}$ from Bos taurus showed conversion rates below $0.1 \mathrm{nmol}$ product per nmol P450 per min. The ferredoxins Fdx2 and Fdx8 with their autologous reductase FdR_B showed conversion rates of 0.3 and $0.8 \mathrm{nmol}$ product per nmol P450 per min, respectively. Investigations with spinach redox partners analogous to Tang et al. ${ }^{12}$ lead to conversion rates of $0.2 \mathrm{nmol}$ product per nmol $\mathrm{P} 450$ per min for the described ratio (1.5:100:0.025U for P450:Fdx:FdR). Using optimized reaction conditions (five times higher reductase amount), $0.5 \mathrm{nmol}$ product per nmol P450 per min were observed. Summarizing the results, the utilization of the homologous redox partners Fdx2/FdR_B and Fdx8/FdR_B resulted in an up to 4 times higher conversion rate compared to our results with the spinach redox system, thus presenting a more efficient redox chain for EpoK compared to published results. 


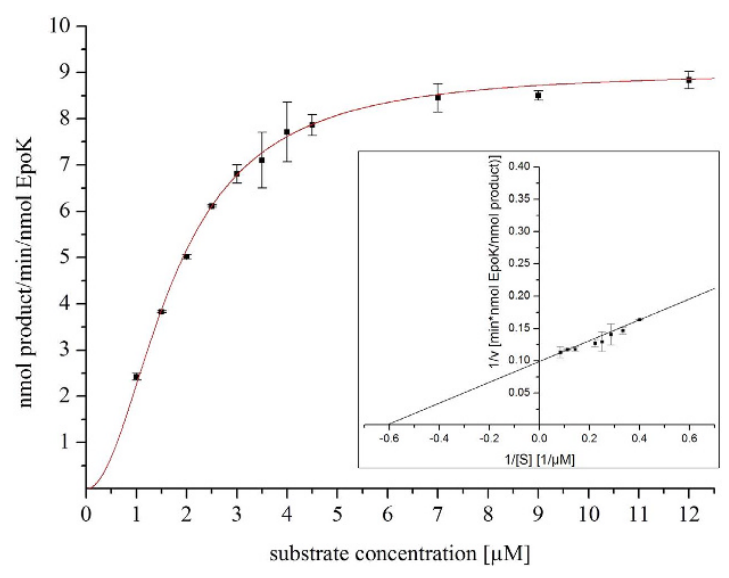

Figure 3. Kinetic studies on epothilone B formation supported by EpoK/SynFdx/FNR hybrid system (ratio 1:20:3 for EpoK:SynFdx:FNR). The Hill model with $n_{H}=2$ resulted in a sigmoidal fit for EpoK kinetics with a coefficient of determination $\left(R^{2}\right)$ of 0.99 . The inset shows the Lineweaver-Burk plot of the data with $\mathrm{R}^{2}=0.99$.

To evaluate the suitability of SynFdx as electron mediator for EpoK, different combinations and ratios of SynFdx with selected reductases were investigated. SynFdx was combined with different heterologous reductases in two different ratios (1:10:1 and 1:20:3 for P450:SynFdx:reductase). To compare the efficiency of the spinach redox system with our results, we calculated conversion rates [nmol product per min per nmol P450] from published data of epothilone $\mathrm{D}$ conversion by EpoK $\mathrm{K}^{12,21}$ to include them into Fig. 2B. All tested combinations, except SynFdx with bovine AdR, resulted in higher conversion rates than described in previous publications. When FdR_B from S. cellulosum So ce56 and Arh1 from $S$. pombe were used as electron donor for SynFdx, slightly higher rates compared to the spinach system were observed. However, the hybrid redox system containing ferredoxin from Synechocystis and FNR from $C$. reinhardtii yielded eight to eleven times (depending on component ratio) higher conversion rates in vitro, compared with the values calculated for spinach Fdx/FNR. Additionally, kinetic studies of the epoxidation of epothilone $\mathrm{D}$ were performed using the ratio 1:20:3 for the EpoK/SynFdx/FNR system. A $\mathrm{V}_{\max }$ value of $9.03 \pm 0.17 \mathrm{nmol}$ product $\mathrm{min}^{-1} \mathrm{nmol}^{-1}$ EpoK and $\mathrm{K}_{1 / 2}=1.73 \pm 0.05 \mu \mathrm{M}$ were obtained by using the Hill-equation (Fig. 3). The replotted Lineweaver-Burk plot of the data (Fig. 3 inset) also showed the similar values of $\mathrm{v}_{\max }$ and $\mathrm{K}_{\mathrm{m}}$ of $10.10 \mathrm{nmol}$ product $\min ^{-1} \mathrm{nmol}^{-1} \mathrm{EpoK}$ and $1.63 \mu \mathrm{M}$, respectively. Compared with literature data $\left(\mathrm{v}_{\max }=5.6 \cdot 10^{-7} \mathrm{nmol}\right.$ product $\min ^{-1} \mathrm{nmol}^{-1}$ EpoK and $\left.\mathrm{K}_{\mathrm{m}}=1.6 \mu \mathrm{M}^{16}\right)$, the $\mathrm{v}_{\max }$ value was increased by seven orders of magnitude $\left(10^{7}\right)$ with a similar $\mathrm{K}_{\mathrm{m}}$ value. Thus, a highly efficient redox chain was established for EpoK.

Bioinformatics identification of potent epothilone D monooxygenases in $S$. cellulosum So ce56. To find additional P450s able to convert epothilones, we investigated the CYPome of So ce56. The phylogenetic comparison of EpoK with the CYPome of So ce56 revealed several P450s of So ce56 closely related to EpoK from So ce90 (Fig. 4A). Among the CYPome of So ce56, the greatest protein sequence homology (approximately 50\%) and identity ( $\geq 30 \%$ ) to EpoK was found for CYP124E1, CYP266A1, CYP267A1 and CYP267B1.

In vitro conversions of epothilone D with selected $\mathrm{P}_{450}$ s from S. cellulosum So ce 56 . CYP266A1, CYP267A1 and CYP267B1 of S. cellulosum So ce56 were tested with respect to their ability to convert epothilone D. Due to low expression levels ${ }^{22}$, CYP124E1 was not studied. But, in addition to the P450 members with the greatest homologies to EpoK, also CYP109, CYP260 and CYP264 families as well as CYP265A1 were further investigated regarding a potential conversion of epothilone D. For this, reconstituted in vitro systems analogous to the ones used for EpoK-dependent epothilone D conversion were used. Interestingly, in contrast to EpoK from So ce90, efforts to apply the hybrid system SynFdx/FNR as an electron transfer system for P450s from So ce56 were unsuccessful. As a result, bovine $\mathrm{Adx}_{4-108} / \mathrm{AdR}$ as well as the autologous Fdx2/FdR_B and Fdx8/FdR_B redox chains were used as described previously ${ }^{22,23}$.

As shown in Table 3, CYP265A1 and CYP266A1 are able to convert epothilone D, with this compound representing the first presently identified substrate for each of these P450s. Interestingly, from the CYP267 family, only CYP267B1 showed activity towards epothilone D. Thus, all of the tested P450s closely related to EpoK, with the exception of CYP267A1, are able to convert epothilone D. In contrast, for the respective CYP109, CYP260 and CYP264 family members, no conversion of epothilone D was observed neither with the heterologous redox partners $\mathrm{Adx}_{4-108} / \mathrm{AdR}$ nor with the autologous electron transfer proteins Fdx2/FdR_B and Fdx8/FdR_B. 

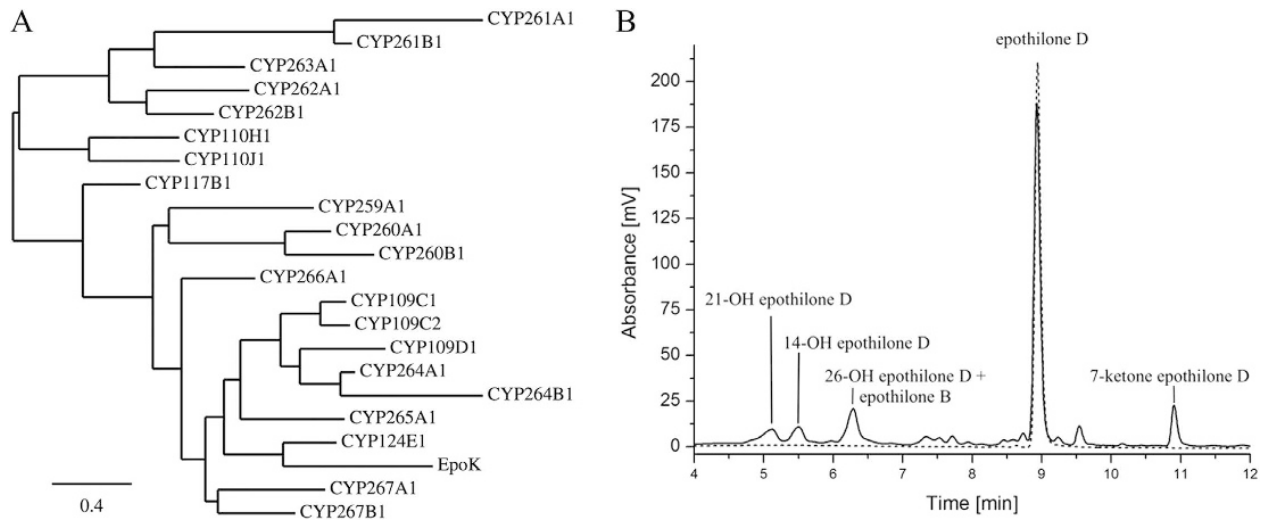

Figure 4. (A) Phylogenetic tree of EpoK and CYPome of So ce56. The tree was constructed by using protein sequences and the "One Click" mode of the online phylogenetic analysis tool from Information Génomique et Structurale, Marseille, France. The bar in the left corner indicates 0.4 amino acid substitutions per amino acid for the branch length ${ }^{65}$. (B) HPLC chromatogram of epothilone D (dashed line) and its conversion by CYP267B1/Fdx8/FdR_B (solid line).

\begin{tabular}{|c|c|c|c|c|c|}
\hline \multirow[b]{2}{*}{ P450 } & \multirow[b]{2}{*}{ Product } & \multirow{2}{*}{$\begin{array}{l}\text { Retention } \\
\text { time [min] }\end{array}$} & \multicolumn{3}{|c|}{ Conversion of epothilone D [\%] with } \\
\hline & & & $\mathrm{Adx}_{4-108} / \mathrm{AdR}$ & Fdx2/FdR_B & Fdx8/FdR_B \\
\hline EpoK & Epothilone B & 6.3 & 6.8 & 24.7 & 74.4 \\
\hline CYP265A1 & $14 \mathrm{OH}$-epothilone D & 5.5 & 3.2 & 5.5 & 6.0 \\
\hline CYP266A1 & $14 \mathrm{OH}$-epothilone $\mathrm{D}$ & 5.5 & l & 6.9 & 2.6 \\
\hline \multirow{5}{*}{ CYP267B1 } & 21-OH epothilone D & 5.1 & 3.5 & 3.2 & 5.5 \\
\hline & 14-OH epothilone D & 5.5 & 3.5 & 3.4 & 4.8 \\
\hline & $\begin{array}{l}\text { 26-OH epothilone } \mathrm{D} / \\
\text { epothilone } \mathrm{B}\end{array}$ & 6.3 & $11.6^{*}$ & $4.0^{*}$ & $11.7^{*}$ \\
\hline & $\begin{array}{c}\text { Not further } \\
\text { characterized product }\end{array}$ & 9.5 & 3.9 & 2.0 & 4.8 \\
\hline & 7-ketone epothilone D & 10.9 & 6.6 & 9.3 & 8.7 \\
\hline
\end{tabular}

Table 3. Epothilone D conversion with selected P450s of S. cellulosum So ce56 (/: no conversion; *: combined yields of 26-OH epothilone D and epothilone B).

Both, CYP265A1 and CYP266A1 were able to catalyze a hydroxylation of epothilone D in position 14 (Table 3, details on identification and characterization of the products via LC-MS/MS see below). Three of the tested redox systems $\left(\mathrm{Adx}_{4-108} / \mathrm{AdR}, \mathrm{Fdx} 2 / \mathrm{FdR} \_\mathrm{B}\right.$ and $\left.\mathrm{Fdx} 8 / \mathrm{FdR} \mathrm{B}\right)$ were able to transfer electrons to CYP265A1, with CYP265A1/Fdx8/FdR_B showing the highest conversion yield (6\% 14-OH epothilone D). CYP266A1 converts epothilone D to 14-OH epothilone D most efficiently when supported by Fdx2/FdR_B (6.9\% conversion), whereas bovine $\mathrm{Adx}_{4-108} / \mathrm{AdR}$ was not able to transfer electrons to CYP266A1. The system yielding the highest total conversion of epothilone D was found to be the autologous CYP267B1/Fdx8/FdR_B system. Most remarkably, the product pattern of CYP267B1 revealed five products of epothilone D conversion (Fig. 4B). Besides 14-OH epothilone D (4.8\% conversion) and 21-OH epothilone D (5.5\% conversion), 26-OH epothilone D and epothilone B were observed and gave a combined conversion of $11.4 \%$. Due to their chemical similarity, 26-OH epothilone and epothilone $\mathrm{B}$ display the same retention time of $6.3 \mathrm{~min}$ (Table 3 and Fig. 4B). However, only small amounts of epothilone B were formed (supplemental Figure S2). Among the apolar products, only the product at $10.9 \mathrm{~min}$ has been characterized and revealed 7-ketone epothilone $\mathrm{D}$ (8.7\% conversion). These products have not been characterized for P450-derived catalysis to date and thus represent novel products. The chemical structures of the identified products are shown in supplemental Figure S1.

LC-MS/MS identification of products formed during in vitro conversion of epothilone D by CYP265A1, CYP266A1 and CYP267B1. Product identification for the in vitro conversion of epothilone D by CYP265A1, CYP266A1 and CYP267B1 was performed by LC-MS/MS analysis. As shown in supplemental Table S1, five epothilone derivatives were obtained and characterized during this study. To elucidate the structures of conversion products and to identify sites of hydroxylation or 


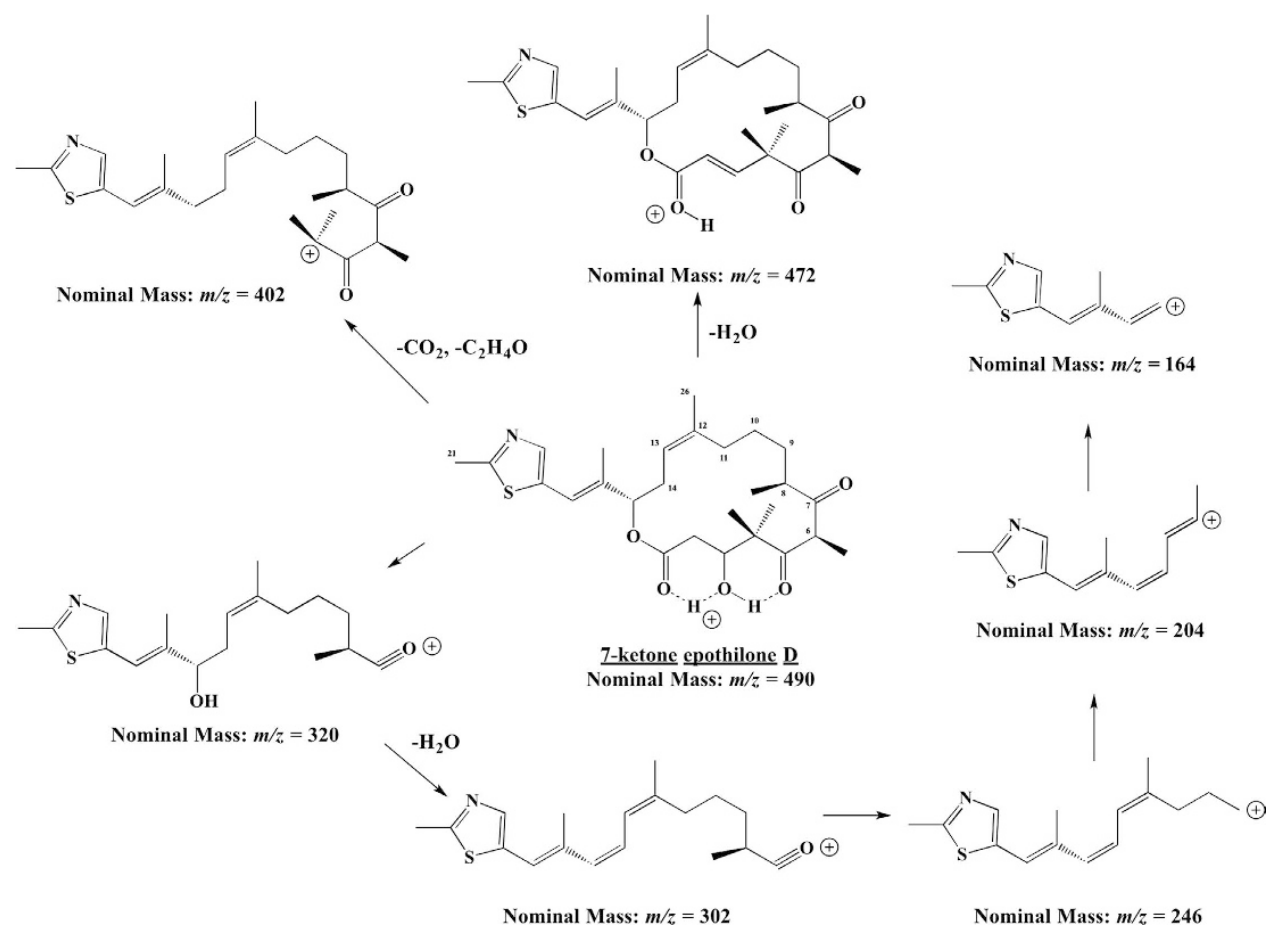

Figure 5. Proposed collision-induced dissociation spectrum of 7-ketone epothilone $D(m / z 490)$. Loss of water at position C-3 results in a fragment with $\mathrm{m} / z$ 472. The fragment ion at $\mathrm{m} / z 402$ appears after the loss of $\mathrm{CO}_{2}$ and $\mathrm{C}_{2} \mathrm{H}_{4} \mathrm{O}$. Step-wise fragmentation of the precursor ion is proposed and presented counterclockwise.

oxidation, CID of the analogous epothilone B compound was performed for comparison purposes. Blum et al. have shown that single or multiple losses of small molecules such as water (18 Da) dominated the CID spectra of epothilone $\mathrm{B}^{24}$. Losses of water originated at positions C-2 and C-3 and/or C-6 and C-7 from the precursor ion or as final step in serial dissociations. Further cleavages occurred at the carbon-oxygen bond at position 15 with formal loss of $\mathrm{CO}_{2}(44 \mathrm{Da})$. Subsequent $\mathrm{C}-\mathrm{C}$ cleavages at various positions in addition to C-O dissociation led to a number of characteristic ions (supplemental Table S1) in our experiments. Several of these product ions (marked with ${ }^{\star}$ ) were also present in the CID spectra of the other products of epothilone D conversion. Tentative structure assignments of the conversion products $\mathrm{A}$ to $\mathrm{D}$ to the general epothilone substance class were therefore readily possible. Substance-specific ions such as $\mathrm{m} / z$ 168, 206 and 220 permitted identification of hydroxylation reactions. In addition, the presence of these ions as well as the precursor ion at $\mathrm{m} / z 508$ pointed to a single hydroxylation site located directly at or near the thiazole ring. The proposed structures of the product ions listed in the supplemental Table S1 allowed us to tentatively assign the products A and B as 21-OH epothilone D, product $\mathrm{C}$ as $14-\mathrm{OH}$ epothilone D, and product D as $26-\mathrm{OH}$ epothilone D (supplemental Figure S2). Conversion product E corresponded to an oxidation product of epothilone B with a specific fragmentation scheme (supplemental Figure S3), which was assigned to the general epothilone substance class. Product E was identified as 7-ketone epothilone D and the proposed collision-induced scheme is illustrated in Fig. 5.

\section{Discussion}

Epothilones belong to a family of novel microtubule-stabilizing agents, which inhibit mitosis. Therefore they are interesting compounds for cancer research and treatment ${ }^{25}$. Their benefits over e.g. paclitaxel as anti-tumor agents are numerous. For example, some studies revealed higher water solubility ${ }^{6}$ and inhibition of cancer cells resistant to various other chemotherapeutic agents ${ }^{7}$. During further studies, additional benefits of a treatment with epothilone $\mathrm{D}$ were described. Low-dose epothilone $\mathrm{D}$ treatment of aged PS19 mice with tau protein malformation in brain neurons (characteristic for Alzheimer disease) led to promising reduction of axonal dysfunction and neurotoxicity ${ }^{10}$. For Parkinson's disease, studies with epothilone D showed a rescue of chemically induced microtubule defects 9 .

CYP167A1 (EpoK) is a P450 enzyme located downstream of the polyketide synthase (PKS) system of $S$. cellulosum So ce90. It is responsible for the last step in epothilone biosynthesis in this organism, resulting in epoxidation of epothilone $D$ to epothilone $B^{21}$. However, detailed information on the redox partners of EpoK, necessary for epothilone A/B formation in S. cellulosum So ce90, are not available. Generally, the P450 systems are classified (class I-X) according to the number, structure and topology of the protein components involved in the electron transfer to the P450 enzyme ${ }^{15}$. Most bacterial P450 
systems belong to class I, in which the systems are composed of three separate proteins. Currently, the only electron transfer system described to support EpoK consists of spinach ferredoxin and spinach ferredoxin $\mathrm{NADP}^{+}$reductase. In 2000, Tang et al. observed a $60 \%$ conversion of epothilone D to B within one hour, using the redox chain from spinach. Attempts to replicate these results during our study resulted in considerably lower yields and conversions rates than described ${ }^{12}$. To find new efficient redox partners for EpoK, different homo- and heterologous class I electron transfer proteins were investigated in the present study.

Several investigations by our group have revealed the bovine $\mathrm{Adx}_{4-108} / \mathrm{AdR}$ electron system as high-profile partner for efficient P450 in vitro and whole-cell experiments with a broad spectrum of P450s of prokaryotic origins supported ${ }^{23,26,27}$. Here, we found that bovine $\mathrm{Adx}_{4-108} / \mathrm{AdR}$ is also able to transfer electrons to the heterologous EpoK from S. cellulosum So ce90. However, conversion of epothilone D by the $\mathrm{EpoK}_{\mathrm{Adx}} \mathrm{Ad}_{4-108} / \mathrm{AdR}$ system led to conversion rates significantly below the described and replicated results with the spinach system. For the electron transfer proteins Etp $1^{\mathrm{fd}}$ and Arh1 from S. pombe, yields and conversion rates for the investigated EpoK/Etp1 $1^{\mathrm{fd}} / \mathrm{Arh} 1$ system were even lower. Despite their ability to provide mammalian P450s with reduction equivalents ${ }^{28,29}$, the application of Etp1 $1^{\mathrm{fd}} / \mathrm{Arh} 1$ (or $\mathrm{Adx}_{4-108}$ / AdR) as electron donor system for EpoK thus remains limited.

After Schneiker et al. sequenced the genome of S. cellulosum So ce56 in $2007^{30}$, our group characterized not only $21 \mathrm{P}^{2} 50 \mathrm{~s}^{22}$ but also 8 ferredoxins and 2 ferredoxin reductases ${ }^{31}$. It was revealed that the combination of Fdx2 and Fdx8 with FdR_B offers suitable electron transfer activities to many myxobacterial P450s, making the So ce56 redox pairs Fdx2/FdR_B and Fdx8/FdR_B interesting targets for in vitro studies with EpoK from So ce90. During this study, it was shown that the utilization of myxobacterial ferredoxin and ferredoxin reductase leads to higher yields and conversion rates compared with bovine $\mathrm{Adx}_{4-108} / \mathrm{AdR}$ or Etp1 $1^{\mathrm{fd}} / \mathrm{Arh} 1$ from $S$. pombe. With regard to the yields described by Tang et al. and Julien et al..$^{12,21}$ and conversion rates calculated based on these data, the homologous EpoK/Fdx8/FdR_B system revealed an efficiency to convert epothilone $\mathrm{D}$ comparable with the results published for the spinach redox chain. Bioinformatics study on the genes of Fdx2, Fdx8 and FdR_B from So ce56 revealed high identity $(93.1 \%, 78.2 \%$ and $92.7 \%)$ to putative ferredoxin and ferredoxin reductase genes of S. cellulosum So0157-2 (supplemental Table S2). Sequenced in 2013 by Han et al. ${ }^{32}$, the So0157-2 strain of S. cellulosum is an alkaline-adaptive producer of glycosylated epothilone A and B derivatives with high relationship to the not yet sequenced So ce90 strain ${ }^{33}$. Thus, the detection of ferredoxin and ferredoxin reductase genes, which are highly similar to the respective genes from So ce56, whose gene products were shown to support EpoK activity, is the first step to identify and ultimately purify the natural redox partners of EpoK from S. cellulosum So ce90.

In order to further optimize in vitro conversions catalyzed by EpoK, novel electron transfer proteins were also tested. We selected ferredoxin (SynFdx) from the unicellular cyanobacterium Synechocystis sp PCC6803 as electron mediator. Synechocystis is a photoautotrophic organism capable of oxygen-producing photosynthesis $^{34}$ and is able to synthesize two different Photosystem-I electron acceptors, a [2Fe-2S] ferredoxin and flavodoxin, both first purified and characterized by Bottin et al. in $1992^{35}$. There are eight other ferredoxins in Synechocystis, but the ferredoxin (SynFdx) chosen for this study presently received the most attention as a result of its diversified involvement in redox processes, such as cyclic photophosphorylation, nitrogen assimilation, biosynthesis of glutamate and chlorophyll, sulfite reduction and fatty acid metabolism ${ }^{36}$. As an additional novel member for an in vitro P450 electron transport chain, ferredoxin $\mathrm{NADP}^{+}$reductase (FNR) from the unicellular green alga C. reinhardtii was included in our studies. The selected FNR, a protein naturally involved in the $\mathrm{NADP}^{+}$reduction in the chloroplast stroma ${ }^{37}$, was first isolated and characterized by Decottignies et al. in $1995^{38}$. A comparison of plant and bacterial ferredoxin- $\mathrm{NAD}(\mathrm{P})^{+}$reductases led to the conclusion that plant ferredoxin-NAD $(\mathrm{P})^{+}$reductases evolved higher efficiency and turnover rates to operate in rapid metabolic pathways such as oxygenic photosynthesis $^{39}$, recommending FNR from $C$. reinhardtii as an interesting partner for in vitro investigations.

The SynFdx/FNR/NADPH hybrid system was recently tested for cytochrome $\mathrm{c}$ reduction ${ }^{40}$. However, the combination of the SynFdx/FNR system with P450s in in vitro experiments remained unexplored. Therefore, we employed two different ratios of the P450 and redox partners (1:10:1 or 1:20:3 for EpoK:SynFdx:FNR) and found that the latter ratio of the hybrid system revealed a significant increase of conversion rates and a complete conversion of $100 \mu \mathrm{M}$ epothilone D to B within one hour. A change in the ratio of EpoK:SynFdx:FNR did not alter the regioselectivity of epothilone D epoxidation. For an efficient electron transfer chain, the formation of short-lived complexes is essential, dictated and controlled by the details of non-covalent interactions ${ }^{41}$. Optimal redox partners can be advantageous to increase the activities of recombinant $\mathrm{P} 450$ systems ${ }^{14}$. Therefore, it is noteworthy that although a reconstituted system with components originating from very different organisms (a myxobacterial P450, a cyanobacterial ferredoxin from Synechocystis and a plant ferredoxin $\mathrm{NADP}^{+}$reductase from C. reinhardtii) was studied, a high efficiency for in vitro conversions was detected.

As shown in Fig. 3, kinetic studies of the EpoK/SynFdx/FNR system resulted in sigmoidal kinetics. It can be assumed that allosteric effects are responsible for the Hill coefficient $n_{H}=2$. Two substrate molecules in the active site, as known for CYP3A4 or CYP2C9 ${ }^{42}$ and already proposed for EpoK ${ }^{16}$, and the special feature of EpoK to be renaturated by its natural substrate epothilone $\mathrm{D}^{16}$, support this assumption. Our regenerated Lineweaver-Burk plot showed that the observed $K_{m}$ value is similar to the one reported in the literature ${ }^{16}$. However, the observed $\mathrm{v}_{\max }$ value is remarkably more than seven orders of magnitude 
$\left(10^{7}\right)$ higher than the one described for EpoK supported by the spinach redox partners ${ }^{16}$, thus rendering the EpoK/SynFdx/FNR system much more attractive for biotechnological application. With possible further improvements of the system in mind, it is also interesting to consider the characteristics of the tested electron transfer partners and their implications for the system: spinach ferredoxin, the first and until this study - only ferredoxin reportedly supporting EpoK, has a low redox potential of $-415 \mathrm{mV}^{43}$. Interestingly, SynFdx, which exhibited the best conversion rates in this study (Fig. 2B), shows the most negative redox potential compared with $\mathrm{Adx}_{4-108}$ and $\mathrm{Etp}^{\mathrm{fd}}$ (Table 1). It is assumed that EpoK generally requires an electron mediator with a rather low redox potential. However, the redox potential is clearly not the only determinant for efficient electron transfer to EpoK since spinach ferredoxin is characterized by a yet lower redox potential than SynFdx.

Moreover, with SynFdx from the phototrophic Synechocystis acting as electron mediator for EpoK, a new way of epothilone B synthesis is imaginable. Recently, Jensen and co-workers described a light-driven hydroxylation of hydrocarbons using mycobacterial CYP124 in combination with spinach Fdx and photosystem I from Hordeum vulgare ${ }^{44}$. Applying SynFdx and photosystem I from Synechocystis as a redox chain for EpoK, a new interesting possibility of a light-driven, NADPH-independent epoxidation of epothilone D might be accessible.

Besides investigation of redox partners for EpoK and conversion of epothilone D to B, we investigated further opportunities for derivatization of epothilone D during this study. As mentioned before, the broad range of applications highlights epothilones as interesting targets for drug design, cancer therapy and pharmaceutical research. The availability and production of epothilones is therefore of great interest to the pharmaceutical industry. In addition to the recently improved extraction methods for epothilones from S. cellulosum fermentation broth ${ }^{45}$, total chemical synthesis of epothilones ${ }^{46}$, precursor-directed biosynthesis ${ }^{47}$ and heterologous production of epothilones in microorganisms ${ }^{48,49}$ are fields of research. Furthermore, also novel derivatives of epothilones are desirable compounds ${ }^{8}$. Investigations towards epothilone derivatives were described using chemical modifications ${ }^{50}$, extraction of derivatives from different S. cellulosum strains ${ }^{51}$, biotransformations with Amycolata autotrophica ${ }^{52}$ or selective conversion of epothilone B to epothilone F with a P450 hydroxylase from Amycolatopsis orientalis ${ }^{53}$. During the past few years, P450s of S. cellulosum So ce56 have revealed a great potential for industrial and biotechnological applications ${ }^{17,20,22,23,54}$. In order to produce potentially useful epothilone derivatives, we selected the members of CYP109, CYP260, CYP264 and CYP267 families as well as CYP265A1 and CYP266A1 from $S$. cellulosum So ce56 to test their ability to convert epothilone D. For the study described here, three different redox systems (P450/Adx ${ }_{4-108} / \mathrm{AdR}, \mathrm{P} 450 / \mathrm{Fdx} 2 / \mathrm{FdR}$ _B and P450/Fdx8/FdR_B) were tested with the P450s mentioned above.

For the members of CYP109, CYP260 and CYP264 families and for CYP267A1, no conversions of epothilone D with any of the redox systems were observed. In contrast, CYP265A1, CYP266A1 and CYP267B1, which were showing high similarity to EpoK (Fig. 4A), were found to be able to convert epothilone D, in which CYP265A1 showed almost similar preference for Fdx2/FdR_B and Fdx8/FdR_B followed by $\mathrm{Adx}_{4-108} / \mathrm{AdR}$ (Table 3). However, CYP266A1 preferred Fdx2/FdR_B followed by Fdx8/ FdR_B and has no activity with $\mathrm{Adx}_{4-108} / \mathrm{AdR}$ (Table 3). Although the conversion percentage was different, there was no change in the regioselectivity of hydroxylation, thus highlighting the use of the autologous redox systems for P450s of S. cellulosum So ce56 in future whole-cell studies. It is, however, interesting to mention that the use of different redox partners for CYP267B1 revealed different regioselectivity of epothilone D oxidation, in which the combination of CYP267B1 with Fdx8/FdR_B and $\mathrm{Adx}_{4-108} /$ AdR preferred the $26-\mathrm{OH}$ epothilone $\mathrm{D} /$ epothilone $\mathrm{B}$ product followed by 7-ketone epothilone D, whereas Fdx2/FdR_B showed a preference for 7-ketone epothilone D formation (Table 3). It can be assumed that the different ferredoxins mediate the electron flow to CYP267B1 with different efficiency and are, therefore, affecting the product distribution. An effect of different redox partner combinations on the regioselectivity of substrate hydroxylation has also been observed for $\mathrm{P} 450 \mathrm{MycG}^{55}$.

The products of epothilone D conversion, 14-OH, 21-OH and 26-OH epothilone $\mathrm{D}$, can currently only be obtained via biotransformation of epothilone D by Amycolata autotrophica ${ }^{52}$, as natural products of So ce90/B2 and So ce90/D13 $3^{56}$ or via chemical synthesis ${ }^{57}$. Cytotoxic activity data (IC50, MCF7 breast cancer cell line) of $14-\mathrm{OH}(29 \mathrm{nM}), 21-\mathrm{OH}(23 \mathrm{nM})$ and $26-\mathrm{OH}$ epothilone $\mathrm{D}(95 \mathrm{nM})$ were published earlier, with values higher than for epothilone D $(9 \mathrm{nM})$ or $\mathrm{B}(0.5 \mathrm{nM})$, respectively ${ }^{52}$. However, for the first time, we found P450s, which open the possibility of a P450-derived production of 14-OH, $21-\mathrm{OH}$ and $26-\mathrm{OH}$ epothilone $\mathrm{D}$ to perform further studies with those derivatives. Most interestingly, CYP267B1 was able to oxidize epothilone D at position C-7 to 7-ketone epothilone D (Table 3). The positions in the epothilone molecule surrounding position $\mathrm{C}-7$ have been shown to be of importance for the pharmacological effect of this compound. Thus, the removal/insertion of the methyl group, the reduction of the $\mathrm{C}=\mathrm{O}$ group or the extension/reduction of the size of the epothilone $\mathrm{D}$ ring result in a less cytotoxic effect ${ }^{58}$. In contrast, the function of substitutions at position C-7 have currently not been analyzed and need to be further investigated to be able to find a potential pharmacologically active derivative of epothilones.

In summary, our results demonstrate that the redox pair Fdx8/FdR_B from S. cellulosum So ce56 efficiently supports the epothilone D conversion catalyzed by EpoK thus indicating a potential similarity to natural redox partners from So ce90. This hypothesis is supported both by experimental results and bioinformatics study. Apart from Fdx8/FdR_B, several other efficient redox partners were also identified 
in this study, which enable for the first time the implementation of EpoK in semisynthetic ${ }^{47}$, biotechnological ${ }^{49}$ or putatively even light-dependent ${ }^{44}$ epothilone B production. Following the hybrid system of Anabaena ferredoxin-NADP ${ }^{+}$reductase and bovine Adx described in $2003^{59}$, the newly established in vitro hybrid system consisting of SynFdx from Synechocystis and FNR from C. reinhardtii reveals great potential for future EpoK in vitro and whole-cell studies and brings hybrid systems for P450 applications back into discussion.

With regard to the derivatization of epothilone D, eleven myxobacterial P450s have been investigated concerning their respective potential of converting epothilones and three of them were identified to convert epothilone D. Thereby, 14-OH, 21-OH and 26-OH epothilone D were found as novel P450-derived products. Additionally, a new epothilone derivative (7-ketone epothilone $\mathrm{D}$ ) with a potential anti-tumor activity available by CYP267B1-dependent conversion was obtained (Fig. 5). Along with the autologous redox partners from S. cellulosum So ce56, further studies on protein engineering targeting higher yields and selectivity could lead to an important biotechnological application of myxobacterial P450s.

\section{Methods}

Chemicals. Phusion ${ }^{\mathrm{TM}}$ High Fidelity DNA polymerase was purchased from Finnzymes (Espoo, Finland), Fast-Link ${ }^{\mathrm{TM}}$ and DNA ligation kit from EPICENTRE Biotechnologies (Madison, WI, USA). Restriction enzymes were obtained from Promega (Madison, WI, USA). Oligonucleotides were purchased from BioTeZ Berlin-Buch GmbH (Berlin, Germany). Epothilone D was purchased via Biorbyt Ltd. (Cambridge, United Kingdom). Isopropyl B-D-1-thiogalactopyranoside (IPTG) and 5-aminolevulinic acid were purchased from Carbolution chemicals (Saarbruecken, Germany). Bacterial media were purchased from Becton Dickinson (Heidelberg, Germany). All other chemicals were obtained from standard sources in the highest purity available.

Plasmids and strains. The gene encoding EpoK was amplified by polymerase chain reaction (PCR) using the primers EpoK_Bamfor (CAGTGGATCCATATGACACAGGAGCAAGCGAATCAG) and EpoKhis_hindrev (ATGAAGCTTAGTGATGGTGATGGTGATGT-CCAGCTTTGGAGGGCTTCAAG) as well as Phusion ${ }^{\mathrm{TM}}$ High Fidelity DNA polymerase and genomic DNA of S. cellulosum So ce90 as template. The PCR primers introduced a sequence encoding a hexahistidine-tag in front of the stop codon as well as the restriction sites used for cloning into pCWori+. The FNR cDNA fragment coding for the full-length mature protein of Chlamydomonas reinhardtii was inserted into the pET-3d plasmid between the restriction sites $\mathrm{NcoI}$ and BamHI giving rise to the construct pET-FNR. The construct was designed in such a way that the $\mathrm{N}$ - and C-termini of the recombinant protein were MASLRKPS and NQWHVEVY, respectively. The E. coli strain BL21 (DE3) for the heterologous expression of the P450s was purchased from Agilent Technologies (Santa Clara, CA, USA).

Bioinformatics. Pairwise protein sequence alignments were performed using the Needlemann-Wunsch algorithm (EMBL-EBI: Needle (EMBOSS)). Protein sequences were taken from NCBI protein database (UniProtKB).

Heterologous expression and purification of P450s. E. coli BL21 (DE3) cells were transformed with the pCWori_EpoK plasmid encoding the C-terminal hexahistidine-tagged EpoK from S. cellulosum So ce90. An overnight culture was prepared from a single colony and was grown at $37^{\circ} \mathrm{C}$ in lysogeny broth (LB) medium ( $10 \mathrm{~g}$ tryptone, $5 \mathrm{~g}$ yeast extract and $10 \mathrm{~g} \mathrm{NaCl}$ per liter $\mathrm{H}_{2} \mathrm{O}$ ) containing $100 \mu \mathrm{g} \mathrm{ml}^{-1}$ ampicillin. For the heterologous expression of EpoK, a main culture of $500 \mathrm{ml}$ terrific broth (TB) medium ( $24 \mathrm{~g}$ yeast extract, $12 \mathrm{~g}$ peptone, $4 \mathrm{ml}$ glycerol, $2.31 \mathrm{~g} \mathrm{~K}_{2} \mathrm{HPO}_{4}$ and $12.54 \mathrm{~g} \mathrm{KH}_{2} \mathrm{PO}_{4}$ per liter $\mathrm{H}_{2} \mathrm{O}$ ) containing $100 \mu \mathrm{g} / \mathrm{ml}$ ampicillin was inoculated with $5 \mathrm{ml}$ of the overnight culture and grown at $37^{\circ} \mathrm{C}$. At an optical density $(600 \mathrm{~nm})$ of $0.9,1 \mathrm{mM}$ IPTG and $0.5 \mathrm{mM} 5$-aminolevulinic acid were added. After $24 \mathrm{~h}$ of expression at $25^{\circ} \mathrm{C}$, cells were harvested by centrifugation at $4000 \times \mathrm{g}$ for $20 \mathrm{~min}$. Cell pellets were stored at $-20^{\circ} \mathrm{C}$ until purification. For protein purification, a cell pellet was thawed on ice and resuspended in lysis buffer ( $50 \mathrm{mM}$ Tris- $\mathrm{Cl}$ ( $\mathrm{pH}$ 7.5) buffer with $10 \%$ glycerol, $0.5 \mathrm{M}$ sodium chloride, $5 \mathrm{mM}$ $ß$-mercaptoethanol, $5 \mathrm{mM}$ imidazole and $1 \mathrm{mM}$ phenylmethylsulfonyl fluoride). Cells were disrupted by sonication and the separation of the cytosolic fraction was ensured by centrifugation at 30,000 rpm for $30 \mathrm{~min}$. The supernatant was loaded on a 5 PRIME$^{*}$ PerfectPro $^{*}$ Ni-NTA Agarose column (Fisher scientific, Schwerte, Germany), washed with lysis buffer (twice the volume of packed column) and eluted with a linear gradient from $5 \mathrm{mM}$ to $200 \mathrm{mM}$ imidazole. Fractions of $2 \mathrm{ml}$ were collected and analyzed via UV-Vis spectroscopy (UV- 2101PC, SHIMADZU, Japan). Fractions showing an absorption value $\left(\mathrm{A}_{420 \mathrm{~nm}} / \mathrm{A}_{276 \mathrm{~nm}}\right)$ higher than 1.1 were pooled, washed with storage buffer ( $50 \mathrm{mM}$ Tris- $\mathrm{Cl}(\mathrm{pH} 7.5)$ buffer with $10 \%$ glycerol, $0.5 \mathrm{mM}$ dithiothreitol and $1 \mathrm{mM}$ EDTA) and concentrated using a Centricon ultrafiltration unit with $30-\mathrm{kDa}$ cut-off (Millipore). The concentration of EpoK was determined by recording the oxidized spectra using $\varepsilon(420 \mathrm{~nm}-490 \mathrm{~nm})=110 \mathrm{mM}^{-1} \mathrm{~cm}^{-1} 60$.

The P450s CYP109C1, CYP109C2, CYP109D1, CYP260A1, CYP260B1, CYP264A1, CYP264B1, CYP265A1, CYP266A1, CYP267A1, and CYP267B1 were expressed and purified as described previously ${ }^{17,19,22,23,54}$. 
Heterologous expression and purification of redox partners. The electron transfer partners $\mathrm{Adx}_{4-108}$ and AdR from Bos taurus were expressed and purified as noted elsewhere ${ }^{61,62}$. The ferredoxin $E t p 1^{\text {fd }}$ and the reductase Arh1 from S. pombe were expressed and purified as described ${ }^{28,29}$. The ferredoxins Fdx2 and Fdx8 as well as the reductase FdR_B from S. cellulosum So ce56 were expressed and purified analogous to previous studies in our laboratory ${ }^{31}$.

E. coli BL21(DE3) was transformed with pET3d-FNR (ampicillin resistance) and pSBET (kanamycin resistance), the latter one encoding tRNAs for rare arginine codons ${ }^{63}$ and colonies with double resistance were selected. SynFdx expression was performed from an ampicillin-resistant pCK5-Fdx plasmid in E. coli $\mathrm{DH} 5 \alpha^{64}$. In both cases the antibiotic resistant strains were grown at $37^{\circ} \mathrm{C}$ in $2.41 \mathrm{LB}$ medium supplemented with the required antibiotics (ampicillin at $100 \mu \mathrm{g} \mathrm{ml}^{-1}$ or kanamycin at $50 \mu \mathrm{g} \mathrm{ml}^{-1}$ ) and in the case of SynFdx with additional $50 \mu \mathrm{M} \mathrm{FeSO}_{4}$. Protein expression was induced at exponential phase by adding $100 \mu \mathrm{M}$ IPTG for $4 \mathrm{~h}$ at $37^{\circ} \mathrm{C}$. The cultures were then centrifuged for $15 \mathrm{~min}$ at $4400 \times \mathrm{g}$. The pellets were resuspended in $30 \mathrm{ml}$ of $30 \mathrm{mM}$ Tris- $\mathrm{HCl}$ ( $\mathrm{pH} 8.0$ ), $200 \mathrm{mM} \mathrm{NaCl}$ (Tris- $\mathrm{NaCl}$ buffer).

Cell lysis was performed by sonication $(3 \times 1 \mathrm{~min}$ with intervals of $1 \mathrm{~min})$ and the soluble and insoluble fractions were separated by centrifugation for $30 \mathrm{~min}$ at $35,000 \times \mathrm{g}$. The soluble part was then fractionated in two steps first up to $40 \%$ of the saturation in ammonium sulfate, then up to $80 \%$ for FNR or to $90 \%$ for SynFdx. After centrifugation $(20 \mathrm{~min}, 20,000 \times \mathrm{g})$, the recombinant proteins in the pellets from the 40 to $80 / 90 \%$ ammonium sulfate fractions were purified first by size exclusion chromatography after loading onto an ACA44 $(5 \times 75 \mathrm{~cm})$ column equilibrated in Tris- $\mathrm{NaCl}$ buffer. The fractions containing the highest absorption values (SynFdx: $A_{420 \mathrm{~nm}} / A_{275 \mathrm{~nm}} ;$ FNR: $\mathrm{A}_{455 \mathrm{~nm}} / \mathrm{A}_{275 \mathrm{~nm}}$ ) were pooled, dialyzed by ultrafiltration to remove $\mathrm{NaCl}$ and loaded onto a DEAE (diethylaminoethyl) cellulose column (Sigma-Aldrich, Hannover, Germany) equilibrated in a $30 \mathrm{mM}$ Tris- $\mathrm{HCl}(\mathrm{pH} 8.0)$ buffer. The proteins were then eluted using a 0 to $0.4 \mathrm{M} \mathrm{NaCl}$ gradient. The fractions of interest were pooled, concentrated by ultrafiltration under nitrogen pressure (Amicon, YM10 membrane) and stored in the same buffer at $-20^{\circ} \mathrm{C}$ at concentrations higher than $5 \mathrm{mg} / \mathrm{ml}$. Purified Synechocystis ferredoxin had ratios $\mathrm{A}_{420 \mathrm{~nm}} /$ $\mathrm{A}_{275 \mathrm{~nm}}$ higher than 0.5. Chlamydomonas reinhardtii FNR preparations had ratios $\mathrm{A}_{275 \mathrm{~nm}} / \mathrm{A}_{455 \mathrm{~nm}}$ of about 7. Molecular extinction coefficients of the ferredoxins and ferredoxin reductases expressed and purified during this study are summarized in supplemental Table S0.

In vitro conversions. To measure the in vitro conversion of epothilone $\mathrm{D}$ to $\mathrm{B}$, a reconstituted in vitro system analogous to Julien et al. and Tang et al. was chosen ${ }^{12,21}$. EpoK $(1.5 \mu \mathrm{M})$, the regeneration system consisting of glucose-6-phosphate $(3.3 \mathrm{mM})$ and glucose-6-phosphate dehydrogenase $(0.5 \mathrm{U})$, and epothilone $\mathrm{D}(100 \mu \mathrm{M})$ were used for each sample. The ratios of EpoK to the tested ferredoxins and reductases were selected corresponding to previous studies. In vitro conversions with bovine electron transfer partners were done using a ratio EpoK:Adx ${ }_{4-108}$ :AdR of 1:20:322 and the ratio of the redox partners from S. cellulosum So ce56 were chosen as 1:60:3 (both EpoK:Fdx2:FdR_B and EpoK:Fdx8:FdR_B) corresponding to published values ${ }^{31}$. The ratio for the electron transfer system from $S$. pombe was set as 1:8:0.8 (EpoK:Etp1 ${ }^{\mathrm{fd}}:$ Arh1) as described by Ewen et al..$^{29}$. Ferredoxin from Synechocystis (SynFdx) was tested with different heterologous reductases (ratio EpoK:SynFdx:reductase 1:10:1 and 1:20:3). The total volume of the reaction was $200 \mu \mathrm{l}$. The reaction was started by the addition of NADPH $(1 \mathrm{mM})$. After $1 \mathrm{~h}$ at $30^{\circ} \mathrm{C}$ the reaction was quenched by adding ethyl acetate $(400 \mu \mathrm{l})$. The aqueous phase was extracted twice with ethyl acetate $(2 \times 400 \mu \mathrm{l})$, unified and evaporated to dryness. All experiments were done twice and a negative control without P450 was implemented to verify the P450-dependent reaction.

In vitro conversions with P450s from S. cellulosum So ce56 were done as described before with potassium phosphate buffer $(50 \mathrm{mM}, \mathrm{pH} 7.4,1 \%$ glycerin) as reaction buffer.

Kinetic studies of epothilone D epoxidation by EpoK/SynFdx/FNR system were performed analogous to the reconstituted in vitro system described above. EpoK concentration was set as $0.25 \mu \mathrm{M}$ with an EpoK:SynFdx:FNR ratio of 1:20:3. The reaction was stopped after $90 s$ at $30^{\circ} \mathrm{C}$ by freezing the samples in liquid nitrogen.

Analysis of the in vitro conversions via HPLC. The HPLC analysis was performed on a Jasco (Gross-Umstadt, Germany) HPLC system 2000. The samples were dissolved in $100 \mu \mathrm{l}$ acetonitrile and analyzed (samples of kinetics twice) on a reversed phase column (125/4 Nucleodur 100-5 C18ec, Macherey Nagel, Düren, Germany) at a flow rate of $1 \mathrm{ml} \mathrm{min}^{-1}$ and a temperature of $40^{\circ} \mathrm{C}$ with the gradient: $80 \%$ solvent A (80:20 (v/v) water-acetonitrile) for $1 \mathrm{~min}$, linear gradient for $8.5 \mathrm{~min}$ from $20 \%$ to $90 \%$ solvent B ( $100 \%$ acetonitrile) and holding $90 \%$ solvent B for 4 min. The injection volume was set as $20 \mu \mathrm{l}$ (40 $\mu \mathrm{l}$ for kinetic studies) and the sample was monitored at $250 \mathrm{~nm}$.

Analysis of the in vitro conversions via LC-MS/MS. Mass spectrometric analyses were performed using a Thermo-Fischer (Sunnyvale, CA, USA) Dionex UltiMate 3000 ultra-high performance liquid chromatography (UHPLC) system coupled to an AB Sciex (Concord, ON, Canada) QTRAP 5500 quadrupole linear ion trap (QqLIT) system. Samples were separated on a reversed-phase HPLC column (125/4 Nucleodur 100-5 C18ec, Macherey Nagel) at $40^{\circ} \mathrm{C}$ using gradient elution at $0.5 \mathrm{~mL} \mathrm{~min}{ }^{-1}$. The mobile phase consisted of 80:20 (v/v) water-acetonitrile (A) and 100\% acetonitrile (B). The gradient was as follows: B was increased from 20 to $90 \%$ within $17 \mathrm{~min}$, held there for $5 \mathrm{~min}$, and then returned to $20 \%$ within $0.1 \mathrm{~min}$, followed by an equilibration period at $20 \%$ B for $7.9 \mathrm{~min}$. For each analysis, $10 \mu \mathrm{l}$ were 
injected. ESI-MS conditions were as follows: curtain gas: 55 psi, electrospray voltage: $5 \mathrm{kV}$, source heater temperature: $350^{\circ} \mathrm{C}$, ion source gas 1: $45 \mathrm{psi}$, ion source gas 2: $50 \mathrm{psi}$, collision gas: nitrogen, declustering potential: $48 \mathrm{~V}$, entrance potential: $11 \mathrm{~V}$. MS/MS experiments were performed using collision-induced dissociation (CID) between $15-35 \mathrm{~V}$ for the precursor ion $\mathrm{m} / z$ 508. The collision cell exit potential was $13 \mathrm{~V}$; an isolation width of $1 \mathrm{u}$ was used.

\section{References}

1. WHO. Decisions and list of resolutions of the 65th World Health Assembly: prevention and control of noncommunicable diseases-follow-up to the high-level meeting of the United Nations General Axssembly on the prevention and control of noncommunicable diseases (A65/DIV/3). Report (2012).

2. Allemani, C. et al. Global surveillance of cancer survival 1995-2009: analysis of individual data for 25, 676, 887 patients from 279 population-based registries in 67 countries (concord-2). Lancet, 385(9972), 977-1010 (2015).

3. Dall'Acqua, S. Natural products as antimiotic agents Curr. Top. Med. Chem. 14, 2272-2285 (2014)

4. Mukhtar, E., Adhami, V. M. \& Mukhtar, H. Targeting microtubules by natural agents for cancer therapy. Mol. Cancer Ther. 13(2), 275-284 (2014).

5. Gerth, K., Bedorf, N., Höfle, G., Irschik, H. \& Reichenbach, H. Epothilones A and B: antifungal and cytotoxic compounds from Sorangium cellulosum (Myxobacteria). Production, physico-chemical and biological properties. J Antibiot (Tokyo), 49(6), 560-3 (1996).

6. Höfle, G. et al. Epothilone A and B - Novel 16-membered macrolides with cytotoxic activity: Isolation, crystal structure, and conformation in solution. Angew. Chem., Int. Ed. Engl. 35(13-14), 1567-1569 (1996).

7. Bollag, D. M. et al. Epothilones, a new class of microtubule-stabilizing agents with a taxol-like mechanism of action. Cancer Res. 55, 2325-2333 (1995).

8. Brogdon, C. F., Lee, F. Y. \& Canetta, R. M. Development of other microtubule-stabilizer families: the epothilones and their derivatives. Anticancer Drugs. 25(5), 599-609 (2014).

9. Cartelli, D. et al. Microtubule alterations occur early in experimental parkinsonism and the microtubule stabilizer epothilone D is neuroprotective. Sci. Rep. 3, 1837 (2013).

10. Zhang, B. et al. The microtubule-stabilizing agent, epothilone D, reduces axonal dysfunction, neurotoxicity, cognitive deficits, and Alzheimer-like pathology in an interventional study with aged tau transgenic mice. J Neurosci. 32(11), 3601-11 (2012).

11. Molnár, I. et al. The biosynthetic gene cluster for the microtubule-stabilizing agents epothilones A and B from Sorangium cellulosum So ce90. Chem. Biol., 7(2), 97-109 (2000).

12. Tang, L. et al. Cloning and heterologous expression of the epothilone gene cluster. Science. 287(5453), 640-2 (2000).

13. Bernhardt, R. Cytochromes P450 as versatile biocatalysts. J. Biotechnol., 124(1), 128-45 (2006).

14. Bernhardt, R. \& Urlacher, V. B. Cytochromes P450 as promising catalysts for biotechnological application: chances and limitations. Appl Microbiol Biotechnol. 98(14), 6185-203 (2014).

15. Hannemann, F., Bichet, A., Ewen, K. M. \& Bernhardt, R. Cytochrome P450 systems-biological variations of electron transport chains. Biochim Biophys Acta. 1770(3), 330-44 (2007).

16. Ogura, H. et al. EpoK, a Cytochrome P450 involved in biosynthesis of the anticancer agents epothilones A and B. Substratemediated rescue of a P450 Enzyme. Biochemistry. 43, 14712-14721 (2004).

17. Khatri, Y. et al. A natural heme-signature variant of CYP267A1 from Sorangium cellulosum So ce56 executes diverse omegahydroxylation. FEBS J. 282(1), 74-88 (2015).

18. Litzenburger, M., Kern, F., Khatri, Y. \& Bernhardt, R. Conversions of tricyclic antidepressants and antipsychotics with selected P450s from Sorangium cellulosum So ce56. Drug Metab Dispos, 43(3), 392-9 (2015).

19. Ly, T. T., Khatri, Y., Zapp, J., Hutter, M. C. \& Bernhardt, R. CYP264B1 from Sorangium cellulosum So ce56: a fascinating norisoprenoid and sesquiterpene hydroxylase. Appl Microbiol Biotechnol. 95(1), 123-33 (2012).

20. Schifrin, A. et al. Characterization of the gene cluster CYP264B1-geoA from Sorangium cellulosum So ce56: Biosynthesis of (+)-eremophilene and its hydroxylation. ChemBioChem. 16(2), 337-344 (2015).

21. Julien, B. et al. Isolation and characterization of the epothilone biosynthetic gene cluster from Sorangium cellulosum. Gene. 249(1-2), 153-60 (2000).

22. Khatri, Y. et al. The CYPome of Sorangium cellulosum So ce56 and identification of CYP109D1 as a new fatty acid hydroxylase. Chem Biol, 17(12), 1295-305 (2010).

23. Ringle, M., Khatri, Y., Zapp, J., Hannemann, F. \& Bernhardt, R. Application of a new versatile electron transfer system for cytochrome P450-based Escherichia coli whole-cell bioconversions. Appl Microbiol Biotechnol. 97(17), 7741-54 (2013).

24. Blum, W. et al. In vivo metabolism of epothilone B in tumor-bearing nude mice: identification of three new epothilone B metabolites by capillary high-pressure liquid chromatography/mass spectrometry/tandem mass spectrometry. Rapid Commun. Mass Spectrom., 15(1), 41-49 (2001).

25. Prota, A. E. et al. Molecular mechanism of action of microtubule-stabilizing anticancer agents. Science. 339(6119), 587-90 (2013).

26. Gerber, A., Hannemann, F., Bleif, S., Kleser, M. \& Bernhardt, R. Inventors; SANOFI, Inc., assignee. Whole-cell system for Cytochrome P450 monooxygenases biocatalysis. (2014). WIPO Patent Application WO/2014/202627.

27. Janocha, S. \& Bernhardt, R. Design and characterization of an efficient CYP105A1-based whole-cell biocatalyst for the conversion of resin acid diterpenoids in permeabilized Escherichia coli. Appl Microbiol Biotechnol. 97(17), 7639-49 (2013).

28. Bureik, M., Schiffler, B., Hiraoka, Y., Vogel, F. \& Bernhardt, R. Functional expression of human mitochondrial CYP11B2 in fission yeast and identification of a new internal electron transfer protein, etp1. Biochemistry. 41(7), 2311-2321 (2002).

29. Ewen, K. M., Schiffler, B., Uhlmann-Schiffler, H., Bernhardt, R. \& Hannemann, F. The endogenous adrenodoxin reductase-like flavoprotein arh1 supports heterologous cytochrome P450-dependent substrate conversions in Schizosaccharomyces pombe. FEMS Yeast Res. 8(3), 432-41 (2008).

30. Schneiker, S. et al. Complete genome sequence of the myxobacterium Sorangium cellulosum. Nat. Biotechnol. 25(11), 1281-1289 (2007).

31. Ewen, K. M. et al. Genome mining in Sorangium cellulosum So ce56: identification and characterization of the homologous electron transfer proteins of a myxobacterial cytochrome P450. J Biol Chem. 284(42), 28590-8 (2009).

32. Han, K. et al. Extraordinary expansion of a Sorangium cellulosum genome from an alkaline milieu. Sci. Rep. 3(2101), (2013).

33. Zhao, L. et al. Glycosylation and production characteristics of epothilones in alkali-tolerant Sorangium cellulosum strain So01572. J. Microbiol. 48(4), 438-444 (2010).

34. Kaneko, T. Structural analysis of four large plasmids harboring in a unicellular cyanobacterium, Synechocystis sp. PCC 6803. DNA Res. 10(5), 221-228 (2003).

35. Bottin, H. \& Lagoutte, B. Ferrodoxin and flavodoxin from the cyanobacterium Synechocystis sp PCC 6803. Biochimi Biophys Acta, 1101(1), 48-56 (1992). 
36. Cassier-Chauvat, C. \& Chauvat, F. Function and regulation of ferredoxins in the cyanobacterium, Synechocystis PCC6803: Recent advances. Life (Basel). 4(4), 666-80 (2014).

37. Jacquot, J. P. et al. Residue Glu-91 of Chlamydomonas reinhardtii ferredoxin is essential for electron transfer to ferredoxinthioredoxin reductase. FEBS. 400, 293-296 (1997).

38. Decottignies, P., Le Maréchal, P., Jacquot, J. P., Schmitter, J. M. \& Gadal, P. Primary structure and post-translational modification of ferredoxin-NADP+ reductase from Chlamydomonas reinhardtii. Arch. Biochem. Biophys. 316(1), 249-259 (1995).

39. Ceccarelli, E. A., Arakaki, A. K., Cortez, N. \& Carrillo, N. Functional plasticity and catalytic efficiency in plant and bacterial ferredoxin-NADP(H) reductases. Biochim. Biophys. Acta. 1698(2), 155-65 (2004).

40. Chibani, K., Tarrago, L., Schürmann, P., Jacquot, J. P. \& Rouhier, N. Biochemical properties of poplar thioredoxin z. FEBS Lett. 585(7), 1077-1081 (2011).

41. Palma, P. N., Lagoutte, B., Krippahl, L., Moura, J. J. \& Guerlesquin, F. Synechocystis ferredoxin/ferredoxin-NADP+ reductase/ NADP + complex: Structural model obtained by NMR-restrained docking. FEBS Lett. 579(21), 4585-90 (2005).

42. Davydov, D. R. \& Halpert, J. R. Allosteric P450 mechanisms: multiple binding sites, multiple conformers, or both? Expert Opin. Drug Metab. Toxicol. 4(12), 1523-1535 (2008).

43. Cammack, R. et al. Midpoint redox potentials of plant and algal ferredoxins. Biochem J. 168(2), 205-9 (1977).

44. Jensen, K., Johnston, J. B., Ortiz de Montellano, P. R. \& Møller, B. L. Photosystem I from plants as a bacterial cytochrome P450 surrogate electron donor: terminal hydroxylation of branched hydrocarbon chains. Biotechnol Lett. 34(2), 239-45 (2012).

45. Yang, H. et al. Preparative isolation and purification of epothilones from Sorangium cellulosum fermentation broth by highspeed counter-current chromatography. J. Liq. Chromatogr. Relat. Technol. 38(1), 123-127 (2014).

46. Mulzer, J., Altmann, K. H., Höfle, G., Müller, R. \& Prantz, K. Epothilones - A fascinating family of microtubule stabilizing antitumor agents. C. R. Chim. 11(11-12), 1336-1368 (2008).

47. Boddy, C. N., Hotta, K., Tse, M. L., Watts, R. E. \& Khosla, C. Precursor-directed biosynthesis of epothilone in Escherichia coli. J Am Chem Soc, 126(24), 7436-7 (2004).

48. Julien, B. \& Shah, S. Heterologous expression of epothilone biosynthetic genes in Myxococcus xanthus. Antimicrob. Agents Chemother. 46(9), 2772-8 (2002).

49. Mutka, S. C., Carney, J. R., Liu, Y. \& Kennedy, J. Heterologous production of epothilone C and D in Escherichia coli. Biochemistry. 45(4), 1321-1330 (2006).

50. Zhang, H., Wang, K., Cheng, X., Lu, Y. \& Zhang, Q. Synthesis and in vitro cytotoxicity of poly(ethylene glycol)-epothilone B conjugates. J. Appl. Polym. Sci. 131(23), (2014).

51. Lu, C., Zhao, L. \& Li, Y. Four natural epothilone derivatives isolated from Sorangium cellulosum strain So0157-2. J Chin. Pharmaceutical Sci. 22(1), 28-31 (2013).

52. Tang, L., Qiu, R., Li, Y. \& Katz, L. Generation of novel epothilone analogs with cytotoxic activity by biotransformation. J. Antibiot. 56(1), 16-23 (2003).

53. Basch, J. \& Chiang, S. J. Cloning and expression of a cytochrome P450 hydroxylase gene from Amycolatopsis orientalis: hydroxylation of epothilone B for the production of epothilone F. J. Ind. Microbiol. Biotechnol., 34(2), 171-176 (2007).

54. Khatri, Y. et al. Novel family members of CYP109 from Sorangium cellulosum So ce56 exhibit characteristic biochemical and biophysical properties. Biotechnol Appl Biochem, 60(1), 18-29 (2013).

55. Zhang, W. et al. New reactions and products resulting from alternative interactions between the P450 enzyme and redox partners. J. Am. Chem. Soc. 136, 3640-3646 (2014).

56. Hardt, I. H. et al. New natural epothilones from Sorangium cellulosum, strains So ce90/B2 and So ce90/D13: Isolation, structure elucidation, and SAR studies. J. Nat. Prod. 64(7), 847-856 (2001).

57. Nicolaou, K. C., Finlay, M. R. V., Ninkovic, S. \& Sarabia, F. Total synthesis of 26-hydroxy-epothilone B and related analogs via a macrolactonization based strategy. Tetrahedron. 54(25), 7127-7166 (1998).

58. Altmann, K. H., Wartmann, W. \& O’Reilly, T. Epothilones and related structures - a new class of microtubule inhibitors with potent in vivo antitumor activity. Biochim. Biophys. Acta., 1470(3), M79-91 (2000).

59. Faro, M. et al. Insights into the design of a hybrid system between Anabaena ferredoxin-NADP+ reductase and bovine adrenodoxin. Eur. J. Biochem. 270(4), 726-735 (2003).

60. Omura, T. \& Sato, R. The carbon monoxide-binding pigment of liver microsomes. J Biol Chem. 239(7), 2379-2385 (1964).

61. Sagara, Y. et al. Direct expression of adrenodoxin reductase in Escherichia coli and the functional characterization. Biol Pharm Bull. 16(7), 627-30 (1993).

62. Uhlmann, H., Kraft, R. \& Bernhardt, R. C-terminal region of adrenodoxin affects its structural integrity and determines differences in its electron transfer function to cytochrome P450. J Biol Chem. 269(36), 22557-22564 (1994).

63. Rogers, W. J. et al. Isolation of a cDNA fragment coding for Chlamydomonas reinhardtii ferredoxin and expression of the recombinant protein in Escherichia coli. FEBS Lett. 310(3), 240-5 (1992).

64. Glauser, D. A., Bourquin, F., Manieri, W. \& Schurmann, P. Characterization of ferredoxin:thioredoxin reductase modified by site-directed mutagenesis. J Biol Chem, 279(16), 16662-9 (2004).

65. Dereeper, A. et al. Phylogeny.fr: robust phylogenetic analysis for the non-specialist. Nucleic Acids Res. 36, W465-W469 (2008).

66. Grinberg, A. V. et al. Adrenodoxin: Structure, stability, and electron transfer properties. Proteins: Struct., Funct., Genet. 40(4), 590-612 (2000).

67. Schiffler, B. et al. The adrenodoxin-like ferredoxin of Schizosaccharomyces pombe mitochondria. J Inorg Biochem. 98(7), 1229-37 (2004).

68. Tagawa, K. \& Arnon, D. I. Oxidation-reduction potentials and stoichiometry of electron transfer in ferredoxins. Biochim Biophys Acta. 153(3), 602-613 (1968).

69. Hiwatashi, A., Ichikawa, Y., Maruya, N., Yamano, T. \& Aki, K. Properties of crystalline reduced nicotinamide adenine dinucleotide phosphate-adrenodoxin reductase from bovine adrenocortical mitochondria. I. Physicochemical properties of holo- and apoNADPH-adrenodoxin reductase and interaction between non-heme iron proteins and the reductase. Biochemistry. 15(14), 3082-3090 (1976).

70. Decottignies, P., Flesch, V., Gérard-Hirne, C. \& Le Maréchal, P. Role of positively charged residues in Chlamydomonas reinhardtii ferredoxin-NADP+ reductase. Plant Physiol. Biochem. 41(6-7), 637-642 (2003).

71. Kitayama, M., Kitayama, K. \& Togasaki, R. K. A cDNA clone encoding a ferredoxin-NADP+ reductase from Chlamydomonas reinhardtii. Plant Physiol. 106, 1715-1716 (1994).

72. Süss, K. H., Prokhorenko, I. \& Adler, K. In situ association of calvin cycle enzymes, ribulose-1,5-bisphosphate carboxylase/ oxygenase activase, ferredoxin-NADP + reductase, and nitrite reductase with thylakoid and pyrenoid membranes of Chlamydomonas reinhardtii chloroplasts as revealed by immunoelectron microscopy. Plant Physiol. 107, 1387-1397 (1995).

\section{Acknowledgements}

We would like to thank Michael R. Waterman, Vanderbilt University School of Medicine, Nashville, USA, for the gift of the E. coli expression vector pCWori+. Special thanks to Rolf Müller, Saarland University, 
Germany, for the gift of the genomic DNA from S. cellulosum So ce90 and to Nicolas Rouhier, Nancy University, France, for SynFdx purification. We would also like to thank Birgit Heider-Lips, Alexander Schifrin, Tanja Sagadin and Michael Ringle for protein purifications. This work was partially funded by the DFG (Be1343/23) and a grant from Laboratory of Excellence ARBRE (ANR-LABXARBRE-01).

\section{Author Contributions}

F.K. and R.B. conceived the experiments, F.K., T.D., Y.K., K.M.E. and J.P.J. conducted the experiments, F.K., T.D. and D.V. analyzed the results. All authors reviewed the manuscript.

\section{Additional Information}

Supplementary information accompanies this paper at http://www.nature.com/srep

Competing financial interests: The authors declare no competing financial interests.

How to cite this article: Kern, F. et al. Highly Efficient CYP167A1 (EpoK) dependent Epothilone B Formation and Production of 7-Ketone Epothilone D as a New Epothilone Derivative. Sci. Rep. 5, 14881; doi: 10.1038/srep14881 (2015).

(c) (i) This work is licensed under a Creative Commons Attribution 4.0 International License. The images or other third party material in this article are included in the article's Creative Commons license, unless indicated otherwise in the credit line; if the material is not included under the Creative Commons license, users will need to obtain permission from the license holder to reproduce the material. To view a copy of this license, visit http://creativecommons.org/licenses/by/4.0/ 